\title{
Oral Appliance Therapy Should be Reimbursed as a First-Line Therapy for OSA
}

\author{
Jennifer Q. Le, DMD, D.ABDSM, CPCC ${ }^{1}$, Jeff L. Rodgers, DMD, D.ABDSM, D.ASBA ${ }^{2}, K_{\text {Kevin Postol, DDS, D.ABDSM }}^{3}$ \\ ${ }^{1}$ Wake Dental Sleep Dental Solutions, ${ }^{2}$ Sleep Better Georgia, ${ }^{3}$ Sleep Disordered Dentistry
}

\section{INTRODUCTION}

It is the position of the American Academy of Dental Sleep Medicine (AADSM) that oral appliance therapy (OAT) should be reimbursed as a first-line therapy for the treatment of obstructive sleep apnea (OSA). OAT has been deemed an alternate therapy for OSA, ${ }^{1}$, and numerous studies have indicated that OAT is an effective treatment for sleep-related breathing disorders. ${ }^{2,3}$ The American Academy of Sleep Medicine (AASM) has also acknowledged that OAT should be considered if a patient does not wish to use Continuous Positive Airway Pressure (CPAP) therapy. ${ }^{1}$

In their joint clinical practice guideline, the AADSM and the AASM stated that "[p]atient preference for OAs versus CPAP should be considered by the treating sleep physician before therapy is prescribed." Patient treatment preference and choice can be critical in ensuring that patients experience positive health outcomes. This paper explores evidence regarding patient preference for OAT and how preference may lead to greater adherence and health improvement.

\section{PATIENTS PREFER OAT}

When patients are given the choice between using CPAP or OAT to treat their OSA, studies have indicated that many patients prefer OAT.$^{4-7}$ One study indicated that among patients who completed trials with both OAT and CPAP, approximately $81 \%$ preferred OAT. ${ }^{7}$

In a qualitative study of why patients may choose OAT or CPAP, patients indicated that the most important factors affecting their choice were "device effectiveness, transportability, embarrassment, and cost." "Some of the advantages of oral appliances (OAs) over CPAP are that they are easy to use, ${ }^{6,9}$ easy to transport, ${ }^{9,10}$ comfortable, ${ }^{9}$ and noninvasive, ${ }^{9}$ as well as less noisy ${ }^{9,11}$ and less obtrusive. ${ }^{11}$ Patient preference may lead to more use of and greater compliance with treatment. ${ }^{8}$

\section{PATIENTS ADHERE TO OAT}

When it comes to the treatment of OSA, better compliance leads to better health outcomes and lower healthcare costs. Numerous studies have indicated that adherence to OAT is very high. In one long-term study of OAT adherence, $86 \%$ of patients surveyed continued regular use of their OA over the average course of 3.3 years. Additionally, average nightly use among these respondents was 7.17 hours. ${ }^{12}$ Objective measurement of OAT adherence has also validated patient self-report, with another study indicating that $93 \%$ of patients were compliant with OAT. ${ }^{13}$

In their study comparing OAT to CPAP in terms of health outcomes, Phillips and colleagues found that health outcomes were similar between the two therapies. They hypothesized that patient preference for OAT may have increased adherence, which in turn positively affected health outcomes. ${ }^{14}$ This study highlights the possible relationship between treatment preference and outcomes for patients with OSA.

Untreated sleep apnea may lead to strokes, heart attacks, depression, and myriad health problems that financially drain the healthcare system. The overall cost to the US economy of untreated OSA through comorbidities, accidents, and lost productivity ranges in the billions of dollars. ${ }^{15}$ When patients are unable to comply with treatment, their OSA can go unchecked, resulting in extremely high costs such as emergency room visits and attempts to resolve chronic, life-threatening side effects related to OSA.

OAT is effective in managing these side effects. OAT has been shown effective in resolving OSA symptoms including lowering blood pressure ${ }^{16-18}$ and reducing risk of cardiovascular mortality. ${ }^{19,20}$ Allowing patients to use OAT as a first-line therapy not only improves their health outcomes but also decreases OSA-related healthcare costs.

\section{CONCLUSION}

When it comes to treating OSA, patients must be able to choose their preferred therapy - choice and compliance may go hand in hand. Patients who prefer OAT may be more likely to adhere to treatment, thereby better alleviating their symptoms.

Thus, if patients have a clear preference for OAT over other treatments, it is important to both prescribe and reimburse OAT as a first-line treatment. By insisting that patients utilize other therapies first, even if they do not prefer 
and cannot comply with treatment, we only further delay health improvements and increase healthcare costs. Rather, patient-centered care should be bolstered by allowing patients to choose OAT as their first line of defense against OSA-related complications.

\section{CITATION}

Le JQ, Rodgers JL, Postol K. Oral appliance therapy should be reimbursed as a first-line therapy for OSA. $J$ Dent Sleep Med. 2019;6(1)

\section{REFERENCES}

1. Ramar K, Leslie ;, Dort C, et al. Clinical Practice Guideline for the Treatment of Obstructive Sleep Apnea and Snoring with Oral Appliance Therapy: An Update for 2015 An American Academy of Sleep Medicine and American Academy of Dental Sleep Medicine Clinical Practice Guideline. J Dent Sleep Med. 2015;2(3). doi: $10.15331 /$ jdsm.4868

2. Andrén A, Hedberg P, Walker-Engström M-L, Wahlén P, Tegelberg $\AA$ A. Effects of treatment with oral appliance on 24-h blood pressure in patients with obstructive sleep apnea and hypertension: a randomized clinical trial. Sleep Breath. 2013;17(2):705-712. doi:10.1007/s11325012-0746-7

3. Gotsopoulos H, Chen C, Qian J, Cistulli PA. Oral appliance therapy improves symptoms in obstructive sleep apnea: a randomized, controlled trial. Am J Respir Crit Care Med. 2002;166:743-748. doi:10.1164/rccm.200203-208OC

4. Ferguson KA, Ono T, Lowe AA, Keenan SP, Fleetham JA. A randomized crossover study of an oral appliance vs nasal-continuous positive airway pressure in the treatment of mild-moderate obstructive sleep apnea. Chest. 1996;109(5):1269-1275. doi:10.1378/chest.109.5.1269

5. Ferguson KA, Ono T, Lowe AA, Al-Majed S, Love LL, Fleetham JA. A short-term controlled trial of an adjustable oral appliance for the treatment of mild to moderate obstructive sleep apnoea. Thorax. 1997;52(4):362-368. doi:10.1136/thx.52.4.362

6. Randerath WJ, Heise M, Hinz R, Ruehle KH. An individually adjustable oral appliance vs continuous positive airway pressure in mild-tomoderate obstructive sleep apnea syndrome. Chest. 2002;122(2):569575. doi:10.1378/chest.122.2.569

7. Tan YK, L'Estrange PR, Luo YM, et al. Mandibular advancement splints and continuous positive airway pressure in patients with obstructive sleep apnoea: A randomized cross-over trial. Eur J Orthod. 2002;24(3):239-249. doi:10.1093/ejo/24.3.239

8. Almeida FR, Henrich N, Marra C, et al. Patient preferences and experiences of CPAP and oral appliances for the treatment of obstructive sleep apnea: A qualitative analysis. Sleep Breath. 2013;17(2):659666. doi:10.1007/s11325-012-0739-6

9. American Academy of Dental Sleep Medicine. Oral Appliance Therapy - American Academy of Dental Sleep Medicine. https://www.aadsm.org/oral_appliance_therapy.php. Accessed August 31, 2018.

10. Ferguson K. Oral appliance therapy for obstructive sleep apnea: Finally evidence you can sink your teeth into. Am J Respir Crit Care Med. 2001;163(6):1294-1295. doi:10.1164/ajrccm.163.6.ed1801e

11. Naismith SL, Winter VR, Hickie IB, Cistulli PA. Effect of oral appliance therapy on neurobehavioral functioning in obstructive sleep apnea: a randomized controlled trial. J Clin Sleep Med. 2005;1(4):374-
380. http://jcsm.aasm.org/Articles/010409.pdf. Accessed August 31, 2018.

12. Bachour P, Bachour A, Kauppi P, Maasilta P, Mäkitie A, Palotie T. Oral appliance in sleep apnea treatment: respiratory and clinical effects and long-term adherence. Sleep Breath. 2016;20(2):805-812. doi:10.1007/s11325-015-1301-0

13. Vanderveken OM, Dieltjens M, Wouters K, De Backer WA, Van De Heyning PH, Braem MJ. Objective measurement of compliance during oral appliance therapy for sleep-disordered breathing. Thorax. 2013;68(1):91-96. doi:10.1136/thoraxjn1-2012-201900

14. Phillips CL, Grunstein RR, Darendeliler MA, et al. Health outcomes of continuous positive airway pressure versus oral appliance treatment for obstructive sleep apnea: a randomized controlled trial. Am J Respir Crit Care Med. 2013;187(8):879-887. doi:10.1164/rccm.201212$2223 \mathrm{OC}$

15. Frost \& Sullivan. Hidden Health Crisis Costing America Billions: Underdiagnosing and Undertreating Obstructive Sleep Apnea Draining Healthcare System. Darien, Am Acad Sleep Med 2016. 2016. https://aasm.org/resources/pdf/sleep-apnea-economic-crisis.pdf. Accessed July 19, 2018.

16. Gotsopoulos H, Kelly JJ, Cistulli PA. Oral appliance therapy reduces blood pressure in obstructive sleep apnea: a randomized, controlled trial. Sleep. 2004;27(5):934-941. doi:10.1093/sleep/27.5.934

17. Rietz H, Franklin KA, Carlberg B, Sahlin C, Marklund M. Nocturnal blood pressure is reduced by a mandibular advancement device for sleep apnea in women: findings from secondary analyses of a randomized trial. $J$ Am Heart Assoc. 2018;7(13):e008642. doi:10.1161/JAHA.118.008642

18. Otsuka R, Ribeiro De Almeida F, Lowe AA, Linden W, Ryan F. The effect of oral appliance therapy on blood pressure in patients with obstructive sleep apnea. Sleep Breath. 2006;10:29-36. doi:10.1007/s11325-005-0038-6

19. de Vries GE, Wijkstra PJ, Houwerzijl EJ, Kerstjens HAM, Hoekema A. Cardiovascular effects of oral appliance therapy in obstructive sleep apnea: A systematic review and meta-analysis. Sleep Med Rev. 2018;40:55-68. doi:10.1016/j.smrv.2017.10.004

20. Anandam A, Patil M, Akinnusi M, Jaoude P, El-Solh AA. Cardiovascular mortality in obstructive sleep apnoea treated with continuous positive airway pressure or oral appliance: An observational study. Respirology. 2013;18(8):1184-1190. doi:10.1111/resp.12140

\section{SUBMISSION AND CORRESPONDENCE INFORMATION}

\section{Submitted in final revised form November 30, 2018 Accepted for publication November 30, 2018}

Address correspondence to: Jennifer Q. Le, DMD, D.ABDSM, CPCC, Wake Dental Sleep Dental Solutions, 2810115 Wakefield Pines Dr., Raleigh, NC 27614; Email: jqledmd@gmail.com

\section{DISCLOSURE STATEMENT}

The authors report no conflicts of interest. 